\title{
Deep resistivity imaging across the Northern and Central belts of the Southern Uplands
}

Beamish, D., 1995. Deep resistivity imaging across the Northern and Central belts of the Southern Uplands. Geological Magazine, 132(5), 531-538.

DOI: http://dx.doi.org/10.1017/S0016756800021191

Dr. David Beamish, British Geological Survey

Keyworth, Nottingham NG12 5GG, UK

dbe@bgs.ac.uk

\begin{abstract}
Magnetotelluric data from 16 soundings have provided a northwest-southeast traverse across the Northern and Central belts of the Southern Uplands. The $34 \mathrm{~km}$ profile extends from the Ordovician Portpatrick Formation (northwest of the Thornhill Basin) across the Silurian Gala Group onto the Permian Lochmaben Basin in the southeast. The survey traverses, and has particular relevance to, the Ordovician/ Silurian boundary (Orlock Bridge Fault), the associated Moniaive Shear Zone, and the Moffat Valley Lineament. The data obtained have been successfully modelled (inverted) to provide a crustal-scale resistivity cross-section. The two Upper Palaeozoic basins are resolved as relatively conducting features. Basin depths are about $200 \mathrm{~m}$ (Thornhill) and $1100 \mathrm{~m}$ (Lochmaben). Elsewhere, through the upper crustal interval, resistivities over $500 \mathrm{ohm} \mathrm{m}$ are associated with the Lower Palaeozoic greywackes. The Silurian formations appear more resistive (and slightly thicker) than their Ordovician counterparts. Depth to basement (base Lower Palaeozoic) is not a wellresolved characteristic but resistivity gradients observed below $5 \mathrm{~km}$ suggest a depth of this order. Concealed beneath the Thornhill Basin lie two narrow, vertical, conductive zones. The more substantial feature lies towards the northwest margin of the basin, and is probably associated with the Orlock Bridge Fault. The second zone lies towards the southeast margin of the basin. The conductivity minima, in both cases, are located in the depth range 2 to $3 \mathrm{~km}$; they are separate and distinct from the overlying basin sediments. If the two anomalies, some 5 to $6 \mathrm{~km}$ apart, can be considered an expression of the Moniaive Shear Zone, then the major conductive constituents are concentrated at the margins. Two dipping, resistive features in the upper kilometre are imaged in the vicinity of the Moffat Valley Lineament.
\end{abstract}




\section{Introduction}

This paper combines and summarizes the results from two magnetotelluric (MT) experiments carried out across the Northern and Central belts of the Southern Uplands. The two individual data sets have been previously described and modelled by Beamish $(1991,1992)$. Here, a two-dimensional (2D) model that is consistent with both data sets is described.

Previous 'large-scale' MT work across the Southern Uplands has recently been summarized by Harinarayana, Hutton \& Jones (1993) and by Livelybrooks et al. (1993). These papers provide the most recent crustal/upper mantle scale resistivity models extending from the Alston Block of northern England, northwestwards towards the Southern Uplands Fault. The work described here is a more detailed investigation of deep resistivity variations occurring across the central Southern Uplands in the vicinity of the Thornhill Basin.

\section{The magnetotelluric surveys}

The location map of Figure I shows the 16 MT sites in relation to the geology. The surveys were carried out at a site separation of 2 to $3 \mathrm{~km}$. Upper Palaeozoic inlier basins outlined in Figure 1 include the Thornhill Basin (centre) and the Lochmaben Basin (in the southeast). Both basins represent conductive at-surface features that can be used as a control in the interpretation of the MT data.

Figure 1 displays tract boundaries of the greywacke succession (see, e.g. Stone et al. 1987) as broken lines. The Orlock Bridge Fault (OBF) marks the boundary between fault-defined turbidite formations of Ordovician and Silurian age (Anderson \& Oliver, 1986; Floyd et al. 1987) and, in the area of the surveys, forms the northern margin of the recently mapped Moniaive Shear Zone (MSZ, Barnes, Phillips \& Boland, 1995, this issue). The Moffat Valley Lineament (MVL, Fig. 1) is the regional- scale, geochemical feature discussed by Stone et al. $(1991,1993)$. The Moffat Valley Lineament was an initial 'target' for the 1991 MT survey (sites I to 8). Two-dimensional inversion of the 1991 data suggested a highly conductive zone, at a depth of about $3 \mathrm{~km}$, to the northwest of site 8 (Beamish, 1991).

The 1992 survey (sites 9 to 16) was conducted to investigate this feature further and to provide a 'crustal- scale' (that is, $>30 \mathrm{~km}$ ) profile of data. The offset was employed to avoid access problems caused by the Lowther Hills and to maintain near-surface control by traversing the Thornhill Basin. As is shown here, the second survey did, in fact, resolve the feature 'predicted' by the earlier experiment. The combined MT data sets provide a profile length of $34 \mathrm{~km}$.

Six-channel MT data were collected at a rate of one sounding per day using the BGS field system. Vertical magnetic field (tipper) data were not collected and noise- cancellation was incorporated using two 'local' reference magnetic field channels. The two reference channels were positioned some $200 \mathrm{~m}$ from each sounding centre. MT data are recorded as time-series from directional electric and magnetic field sensors. These data are processed to provide tensor impedance response estimates (both amplitude and phase) as a function of frequency. The frequency bandwidth obtained produces a range of penetration depths. The field data were processed using the robust algorithm of Chave \& Thomson (1989) and provided a sounding bandwidth from about 200 to 0.01 
$\mathrm{Hz}$. This frequency range gives observed minimum penetration depths of about 100 to $200 \mathrm{~m}$ in the more conductive basins and typically 500 to $600 \mathrm{~m}$ within the Lower Palaeozoic turbidites (Beamish, 1992).

\section{Magnetotelluric data characteristics}

Prior to modelling and interpretation, MT tensor data must be assessed for dimensionality and for static (near- surface) distortion effects. The soundings within the basins were clearly influenced by the relatively conductive sediments at the higher frequencies (100 to $1 \mathrm{~Hz}$ ). An analysis of the dimensional weights (Beamish, 1986) shows that, for the majority of soundings, the data at the highest frequencies are predominantly one-dimensional (1D) but with decreasing frequency (increasing penetration), 1D contributions decrease and there is an associated increase in twodimensional (2D) behaviour. The largest 3D effects occur at low frequencies at site 9 (here the 3D weight increases with decreasing frequency and approaches 0.3 ). Localized (near-surface) 3D effects influence the response observed at site 4 . The dimensional characteristics were also confirmed using the classification analysis scheme of Bahr (1991).

In addition to the above, the influence of static distortion was assessed using overlays of sounding curves (measured and rotated) and anisotropy ratios. The assessments suggest that the influence of static distortion on the survey data is minimal. The observed pseudo-sections (see Fig. 2) display an absence of 'vertical-zonation' in apparent resistivities that would characterize the presence of static offsets. In addition, the seven soundings within the two basins all return consistent resistivities for the Permian sediments as described later.

As well as providing information on the dimensionality of the geoelectric structure, MT tensor data are also able to define the principal strike directions of geoelectric anisotropy. The main strength of a profile of MT observations lies in its ability to resolve the cross-sectional (2D) resistivity distribution underlying the profile. The tensor data must first be rotated, as discussed later, into the principal directions of geoelectric anisotropy (in this case, N60E and N150E). In this new coordinate frame the sounding data (both amplitude and phase) provide two 'modes'. The first mode is called the Transverse Electric (TE) mode and corresponds to an electric (E) field parallel to strike. In the plan view of Figure 1, this mode would correspond to an induced electric field flowing along the strike direction of N60E. The second mode is called the Transverse Magnetic (TM) mode and this is associated with a magnetic (M) field parallel to strike. Since corresponding E\&M fields are orthogonal, this mode would correspond to induced currents flowing along N150E (perpendicular to strike) in the plan view of Figure 1.

The data rotated into the principal directions are best viewed as pseudo-sections, that is, contoured frequency/ distance plots of the amplitude and phase variations across the profile. The TM-mode data is particularly useful for examining lateral variations in resistivity structure. The observed pseudo-sections of the TM-mode data along profile a- $d$ are shown in Figures 2 (apparent resistivity) and 3 (phase). Near-surface (high frequency) and deeper (concealed) lateral influences on the joint data can be clearly observed. The two data sets shown represent only one half of the principal observations. A corresponding two data sets are also provided by the TE-mode in which the induced E field is directed along strike. The purpose of 20 modelling is to find a resistivity model which 
simultaneously satisfies both TM- and TE-mode data observed in the principal directions. In the past, attempts to fit such data by trial-and-error forward model- ling proved difficult due to the inherent non-linearity of the problem. Recent advances in 2D inversion, such as the OCCAM algorithm, described later, now allow reliable cross-sectional images of the resistivity distribution to be obtained.

\section{One-dimensional inversion (basin sites 1-2 and 10-13)}

It has already been pointed out that the majority of data appear most one-dimensional at the highest frequencies and the degree of one-dimensionality decreases with decreasing frequency. The data from the basin sites can be analysed for 'depth-to-resistive-basement' using 1D inversion based on the highest frequency data (100 to $1 \mathrm{~Hz}$ ). In order to suppress the residual anisotropy of the sounding data, an invariant is formed using the two off-diagonal impedance elements. This invariant response represents an 'average' over all horizontal azimuths. Three-layer models (two layers + underlying halfspace) were found to provide adequate inversion model misfits over the restricted bandwidth. Only the behaviour of the first discontinuity (layer 1/layer 2) can be adequately determined from the analysis performed.

The inversions at four of the sites within the Thornhill Basin (10, 11, 12, 13, Fig.1) all returned a spatially uniform resistivity of $40 \mathrm{ohm} \mathrm{m}$ for layer 1 that is interpreted as Permian sandstones. Estimated depths to basement (top Lower Palaeozoic) vary as $120 \mathrm{~m}$ (site 10), $193 \mathrm{~m}$ (site 11), $196 \mathrm{~m}$ (site 12) and $237 \mathrm{~m}$ (site 13). The resistivity of the underlying layer returned by the inversions lies between 462 and $724 \mathrm{ohm} \mathrm{m}$. The data from site 14 suggests that the site is too close to the northwest basin margin for 1D analysis to be justified.

A similar analysis for the two sites in the Lochmaben Basin (sites 1 and 2, Fig. 1) indicates depths to basement of $1100 \mathrm{~m}$ (site 1, near the depocentre) and $850 \mathrm{~m}$ (site 2). The sandstones appear more resistive than those of the Thornhill Basin and are approximately $100 \mathrm{ohm} \mathrm{m}$. Again basement (Lower Palaeozoic) resistivities are more than 500 ohm $\mathrm{m}$.

The geoelectric models can be compared with the results of Rollin (unpub. data) who modelled the gravity anomalies in the Dumfries area. Rollin modelled the anomalies over the Thornhill Basin as a subset of the area using a locally modified regional anomaly. Downwards modelling of the residual field over the Permian outcrop produced a depth estimate of $200 \mathrm{~m}$ for the base. For the Lochmaben Basin, the modelling procedure showed a minimum basin depth of $1200 \mathrm{~m}$. The contoured basin depths within the basin suggest a depth of $1100 \mathrm{~m}$ at site 1 and a depth of $700 \mathrm{~m}$ at site 2 (a region of rapid shelving).

\section{Two-dimensional inversion}

Two-dimensional regularized inversions of the data from the two individual surveys were reported by Beamish $(1991,1992)$. Here a 20 model that is consistent with the combined data set is described. A common origin for the combined profiles was taken as $(278 \mathrm{E}, 608 \mathrm{~N})$ and is shown as 'a' on Figure 1. The line $a-b(N 45 W$ ) includes the profile of sites 9 to 16 . The line $c-d$ (again N45W and including sites 1 to 8 ) was then translated onto profile $a-b$, extending the line to the southeast. All site coordinates for the models assume an N45W profile with an origin at $(278 \mathrm{E}, 608 \mathrm{~N})$. The procedure provides a profile length of $34 \mathrm{~km}$. 
In order to perform 2D modelling, the tensor MT data must be rotated to an appropriate geological/geoelectric strike azimuth. Geoelectric strike azimuths were calculated using conventional techniques and the 'regional 2D' strike estimates of Bahr (1991). Both gave similar results. At high frequencies (>10 Hz), 'quadrant swapping' (e.g. NW to NE) as a function of frequency and location suggested structural (resistivity) boundaries being traversed. At lower frequencies (e.g. <.1 Hz), the regional 20 strike azimuths stabilized to a common 'Caledonian' trend of between N50E and N75E.

In order to provide a consistent approach to 20 modelling, all data were rotated to a common azimuth of N60E to provide the TE-mode data (E-field parallel to strike), and an azimuth of N150E was then assumed to provide the TM-mode data (M-field parallel to strike). In order to avoid 3D effects the data from sites 4 and 9 were excluded. Thirteen frequencies (100 to $0.01 \mathrm{~Hz}$ ) from the remaining 14 sites were then used to provide a total of 728 observations (both TE and TM modes) for the inversion procedure.

For the OCCAM2d inversion procedure used (deGroot-Hedlin \& Constable, 1990), a finite-element regularization grid was constructed with node separations $500 \mathrm{~m}$ laterally and $100 \mathrm{~m}$ vertically in the near-surface. These dimensions place limits on the scale of features that can be resolved. The starting model for inversion was a half-space of $300 \mathrm{ohm} \mathrm{m}$. A succession of models with decreasing misfit was obtained during the inversion. The final model used for interpretation has an overall rms misfit of 2.48. Examples of the fits achieved between observed and modelled data are shown in Figures 2 and 3. The comparisons display the TM-mode apparent resistivities (Fig. 2) and associated phase values (Fig. 3) as pseudo-sections.

The OCCAM2d procedure is a regularized, smooth-model inversion and constructs a resistivity crosssection, with the minimum amount of structure that fits the observations. The familiar boundaries and discontinuities of most modelling procedures are deliberately excluded by the OCCAM approach. These are replaced by gradients that 'de-focus' any sharp boundaries in the subsurface. These characteristics should be allowed for in the interpretation of the resistivity cross-sections presented below.

\section{The resistivity model}

The resistivity model obtained to a depth of $5 \mathrm{~km}$ is shown with a vertical exaggeration of $x 4$ in Figure 4. A logarithmic scale of between $3(1000 \mathrm{ohm} \mathrm{m})$ and $1(10 \mathrm{ohm} \mathrm{m})$ is used to contour the resistivity distribution. Near-surface features, especially the thin $(200 \mathrm{~m})$ Thornhill Basin, are difficult to resolve given (a) the site separations of $>2 \mathrm{~km}$ and (b) a near-surface vertical model grid resolution of $100 \mathrm{~m}$. Despite such limitations, the solution images both basins to depths of the correct order. Two at-surface, conductive $(<10 \mathrm{ohm} \mathrm{m})$ zones are imaged towards the northwest and southeast margins of the Thornhill Basin and may be fault-related (mapped faults, other than the Orlock Bridge Fault, are not shown in Fig. 1).

Although observations are limited to the northwest across the Shinnel and Portpatrick formations, these fault-defined Ordovician turbidite sequences are imaged with uniform resistivity values of about 500 ohm m. Two steeply-dipping, resistive zones occur near the Moffat Valley Lineament in the upper kilometre. A more dense set of observations would be required to resolve the feature(s) in detail. The resistive zone with a dip to the southeast appears to be the more substantial feature on the deeper cross-section shown in Figure 5. 
Probably the best resolved features within the cross-section are the two vertical and compact conductive zones underlying the Thornhill Basin at a common depth of about $1.5 \mathrm{~km}$. Simulation modelling (not presented here) of such thin conductive features suggests that their vertical extent is exaggerated by smooth-model inversion. It is likely that the two zones extend only to depths of approximately $3 \mathrm{~km}$ (northwest) and $2.5 \mathrm{~km}$ (south- east). Accurate tie-in of the conductive zones with at-surface features is made difficult by the offsets of the major Caledonian trending features across the Thornhill Basin (Fig. 1); their lateral displacement is approximately 3 to $4 \mathrm{~km}$. It may be that the two conductive features, with a separation of some 5-6 km at depth, can be related to two, high-strain 'edges' of the Moniaive Shear Zone. The concealed conductive zone in the northwest appears to be most closely associated with the Orlock Bridge Fault.

On the image of Figure 4, there is an apparent difference in the bulk resistivities of the Ordovician and Silurian terrains sampled by the profile. These are better viewed in the coarser but deeper crosssection of Figure 5. One interpretation across the upper crustal section (to $10 \mathrm{~km}$ ) is that the faultdefined Silurian tracts are more resistive and thicker (vertically) than the Ordovician tracts to the northwest. Again the vertical extent of 'structure' is exaggerated by the gradients set up in smooth model inversion. If we make the assumption that the Lower Palaeozoic turbidite sequences represent homogeneous units overlying the more conductive material imaged throughout the middle crust, then the 'base' depths of the fault-defined turbidite tracts are approximately $4 \mathrm{~km}$ (Ordovician) and $6 \mathrm{~km}$ (Silurian).

The term base is used above to suggest a transition in resistivity values that could be related to a geological transition from the Lower Palaeozoic to continental basement. The depth estimates obtained here can be compared with estimates of basement depth obtained from seismic experiments. In making the comparison it should be noted that no seismic velocity estimates are available near the present survey and the resistivity model obtained here implies a variation in basement depth perpendicular to the Caledonian trend. Barton (1992) summarizes the seismic results obtained further east in the vicinity of the LISPB experiment (Bamford et al. 1978). Although directional anisotropy of seismic velocities is apparent when the results of various experiments are compared, a relatively shallow depth of between 1 and $5 \mathrm{~km}$ has been inferred for the depth to regional? crystalline basement (Hall et al. 1983).

The mid-crustal resistivities (typically $100 \mathrm{ohm} \mathrm{m}$ ) imaged here are spatially uniform and are consistent with estimates from previous studies throughout the Southern Uplands. Based on the above discussion, these regionally persistent values represent continental basement underlying the Lower Palaeozoic turbidite sequences in the central part of the Southern Uplands.

\section{Summary}

One-dimensional and two-dimensional assessments of the combined magnetotelluric data set across the Northern and Central belts have revealed several important features in the deep subsurface resistivity distribution. The results obtained across the Permian inlier basins, used as near-surface control, showed that the Thornhill Basin, with a bulk sandstone resistivity of $40 \mathrm{ohm}$ $\mathrm{m}$, extends to depths of approximately $200 \mathrm{~m}$. The much deeper Lochmaben Basin, sampled by only two sites, appears more resistive (100 ohm $\mathrm{m}$ ). Estimates of basin depths agree with those obtained by Rollin (unpub. data) when modelling the gravity anomalies in the Dumfries area. Highly 
conductive $(<10 \mathrm{ohm} \mathrm{m})$, at- surface features imaged towards the margins of the Thornhill Basin may be fault-related.

Near the Moffat Valley Lineament two dipping resistive zones are imaged through the uppermost kilometre. More detailed observations, preferably located away from the Permian basins, would provide better resolution of the shallow/deep resistivity relationships (particularly to the southeast) across this geochemically-defined lineament.

The best resolved features of the cross-section (being highly conductive) are the two thin vertical zones, underlying the Thornhill Basin and restricted to depths between 1.5 and $3 \mathrm{~km}$. It has been pointed out that accurate tie-ins with near-surface features are complicated by the offsets of both the Ordovician/Silurian tract boundaries (Orlock Bridge Fault) and Moniaive Shear Zone across the northwest margin of the basin. It would appear that the more substantial conductive feature to the northwest must be interpreted as a deep expression of the laterally variable strain zone mapped at the surface. Recent studies of the Moniaive Shear Zone (Barnes, Phillips \& Boland, 1995, this issue) show a network of several high strain zones. The shear zone is interpreted as resulting from the reactivation of a pre-existing lineament within the basement. The resistivity model appears to confirm the hypothesis. The presence of a major concentration of conductive components (within the rock matrix), due to reactivation and shear, is required to explain the low resistivities observed in the two zones. A resistivity model, by itself, cannot determine the conductive constituents (e.g. minerals or fluids) giving rise to anomalously low resistivity values. In the context of a hypothesis involving reactivation and shear, a plausible mechanism would involve a concentration of a more conducting mineral phase. The regional presence of a conducting phase is already implied at deeper crustal levels to explain the persistence of the relatively low resistivities associated with the basement underlying the Lower Palaeozoic turbidites.

The subsurface resistivity distribution across this section of the Southern Uplands marks the Orlock Bridge Fault and Moniaive Shear Zone as a region of strong lateral gradients through the upper crust. The conductive features underlying the Thornhill Basin represent a dislocation to the otherwise uniform and resistive fault- defined tracts of Lower Palaeozoic turbidites observed to the northwest and southeast. In the southeast, the Silurian turbidite sequences appear thicker and more resistive than the Ordovician sequences to the northwest.

\section{Acknowledgements}

My grateful thanks go to the late Byron Lintern who, with typical vision, initiated the work described here. Reviewers of this paper included Maxine Akhurst, Roger Banks and Ben Doody; my thanks go to all three for their contributions. This paper is published with the approval of the Director, British Geological Survey (NERC).

\section{References}

ANDERSON, T. B. \& OLIVER, G. J. H. 1986. The Orlock Bridge Fault: a major Late Caledonian sinistral fault in the Southern Uplands terrane, British Isles. Transactions of the Royal Society, Edinburgh, Earth Sciences 77, 203-22. 
BAHR, K. 1991. Geological noise in magnetotelluric data: a classification of distortion types. Physics of the Earth and Planetary Interiors 66, 24-38.

BAMFORD, D., NANN, K., PRODEHL, C. \& JACOB, B. 1978. LISPB IV. Crustal structure of Northern Britain. Geophysical Journal of the Royal Astronomical Society 54, 43-60.

BARNES, R. P., PHILLIPS, E. R. \& BOLAND, M. P. 1995. The Orlock Bridge Fault in the Southern Uplands of southwestern Scotland: a terrane boundary? Geological Magazine 132, 523-9.

BARTON, P. J. 1992. LISPB revisited: a new look under the Caledonides of northern Britain. Geophysical Journal International 110, 371-91.

BEAMISH, D. 1986. Geoelectric structural dimensions: methods of estimation, old and new. Geophysics 51, 1298-1309.

BEAMISH, D. 1991. A whole crust resistivity cross-section across the Ae Forest, Southern Uplands. British Geological Survey Technical Report WN/91125.

BEAMISH, D. 1992. Two-dimensional inversion of the Thornhill MT survey data. British Geological Survey Technical Report WN/92114.

CHAVE, A. D. \& THOMSON, D. J. 1989. Some comments on magnetotelluric response function estimation. Journal of Geophysical Research 94, 14215-25.

DEGROOT-HEDLIN, C. \& CONSTABLE, S. 1990. Occam's inversion to generate smooth twodimensional models from magnetotelluric data. Geophysics 55, 1613-24.

FLOYD, J. D., STONE, P., BARNES, R. P. \& LINTERN, B. c. 1987. Constraints on the significance of the Orlock Bridge Fault within the Scottish Southern Uplands. Transactions of the Royal Society, Edinburgh, Earth Science 78, 219-21.

HALL, J., POWELL, D. W., WARNER, M. R., EL-HASA, z. H. M., ADESANYA, 0. \& BLUCK, B. J. 1983. Seismological evidence for shallow crystalline basement in the Southern Uplands of Scotland. Nature 305, 418-20.

HARINARAYANA, T., HUTTON, V. R. S. \& JONES, P. C. 1993. Lateral variations of conductivity structure across Southern Scotland and Northern England. Physics of the Earth and Planetary Interiors 81, 25-41.

LIVELYBROOKS, D., BANKS, R. J., PARR, R. S. \& HUTTON, V.R. S. 1993. Inversion of electromagnetic induction data for the lapetus Suture Zone in the UK. Physics of the Earth and Planetary Interiors 81, 67-84.

STONE, P., FLOYD, J. D., BARNES, R. P. \& LINTERN, B. c. 1987. A sequential back-arc and foreland basin thrust duplex model for the Southern Uplands of Scotland. Journal of the Geological Society, London 144, 753-64.

STONE, P., GREEN, P. M., LINTERN, B. C., PLANT, J. A., SIMPSON, P. R. \& BREWARD, N. 1991. Geochemistry characterizes provenance in southern Scotland. Geology Today 1, 177-81. 
STONE, P., GREEN, P. M., LINTERN, B. C., SIMPSON, P. R. \& PLANT, J. A. 1993. Regional geochemical variation across the lapetus Suture zone: tectonic implications. Scottish Journal of Geology 29, 11321. 


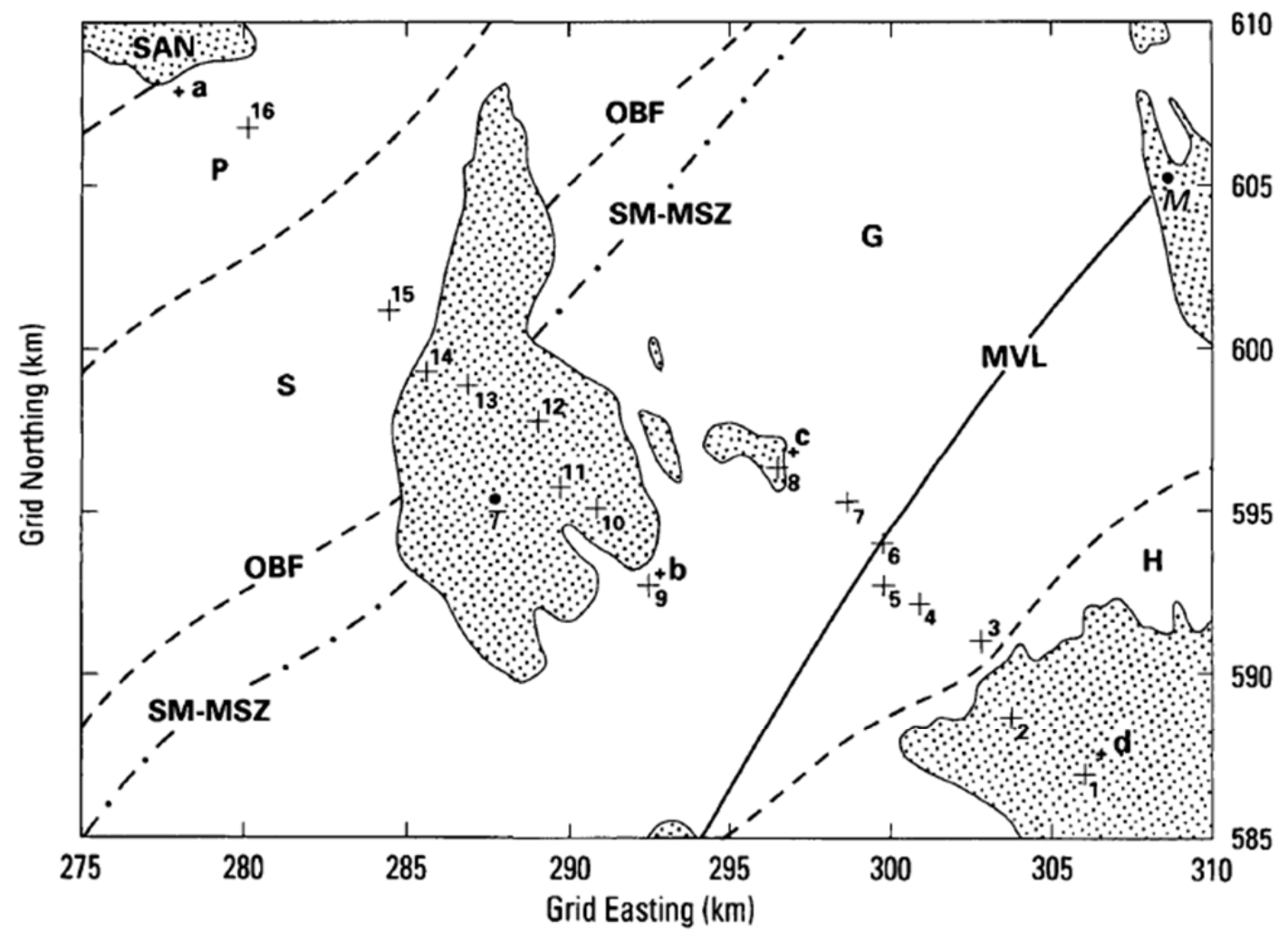

OBF : Orlock-Bridge Fault

SM-MSZ : S. Margin, Moniaive Shear Zone

P : Portpatrick Formation (Ordovician)

MVL : Moffat Valley Lineament

S : Shinnel Formation (Ordovician)

SAN : Sanquhar Basin (Carboniferous)

G : Gala Group (Silurian)

H : Hawick Group (Silurian)

--- Fault

- $M$ : Moffat

- - Southern boundary of Moniaive Shear Zone

- $T$ : Thornhill

- Moffat Valley Lineament

$\because$ Upper Palaeozoic basins

+2 MT survey sites

Figure I. Location map of the magnetotelluric surveys of 1991 (sites I to 8) and 1992 (sites 9 to 16). The two survey profile lines are denoted by the points $a-b$ and c--d. 


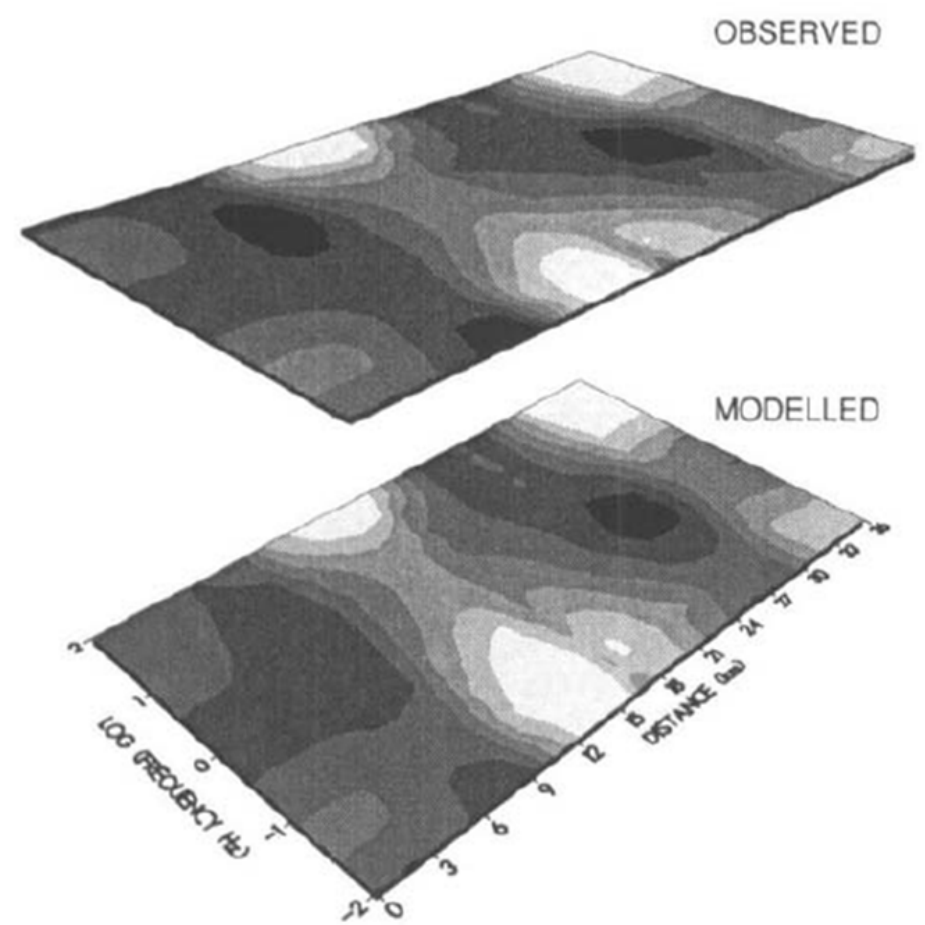

LOG (APP. RES ohm.m)

ABOVE 3.0

$2.8-3.0$

$2.6-2.8$

$2.4-2.6$

$2.2 \cdot 2.4$

$2.0-2.2$

BELOW 2.0

Figure 2. Comparison of the observed and modelled data in the form of contoured pseudo-sections (frequency/distance plots) along profile a-b, c--d (Fig. 1 ). TM-mode apparent resistivities (ohm.m) contoured using a logarithmic scale. The value of 3 represents $1000 \mathrm{ohm} . \mathrm{m}$ and the value of 2 represents 100 ohm.m. 


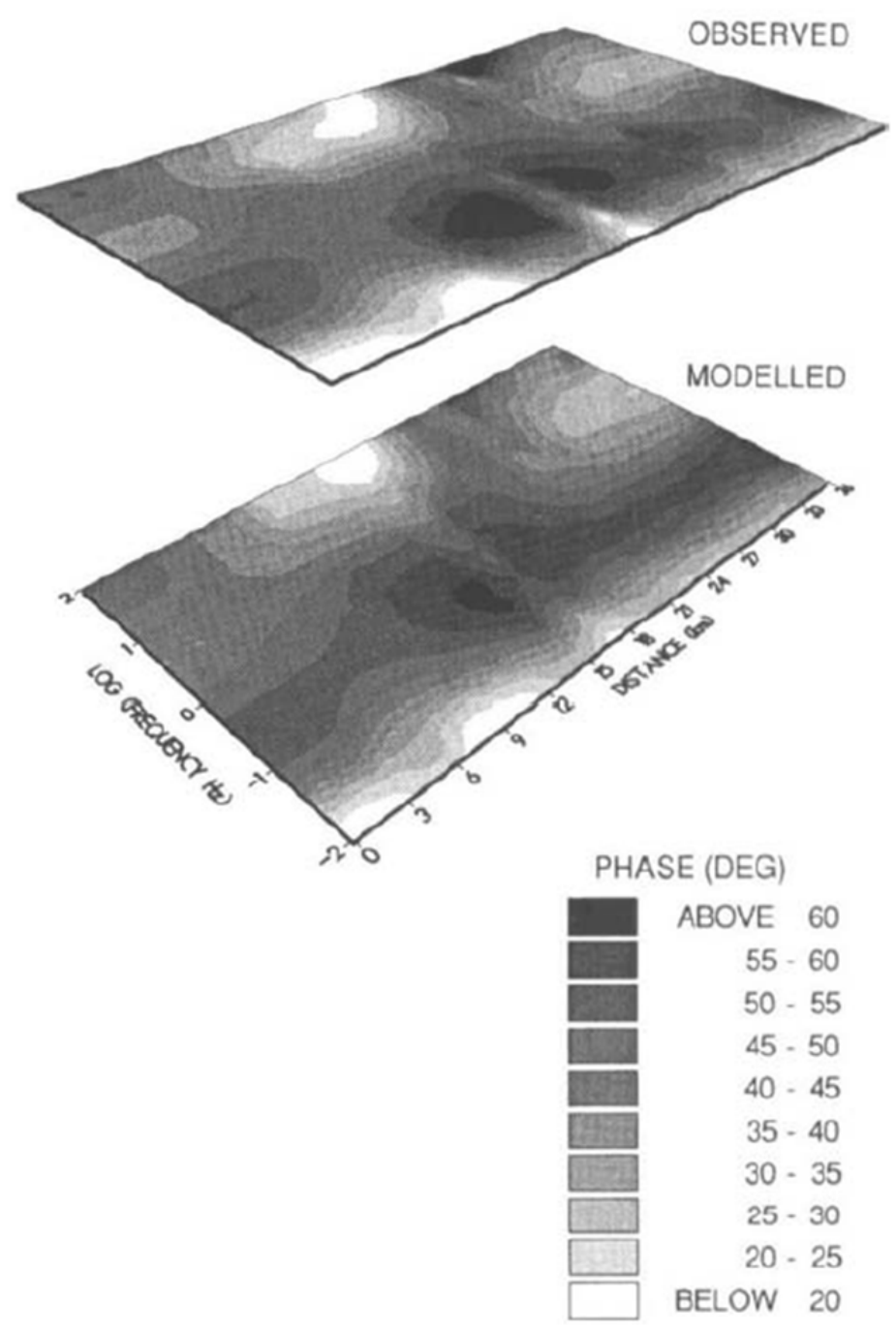

Figure 3. Comparison of the observed and modelled data in the form of contoured pseudo-sections (frequency/distance plots) along profile a-b, c--d (Fig. 1 ). TM-mode phase values (degrees) contoured using a linear scale. 

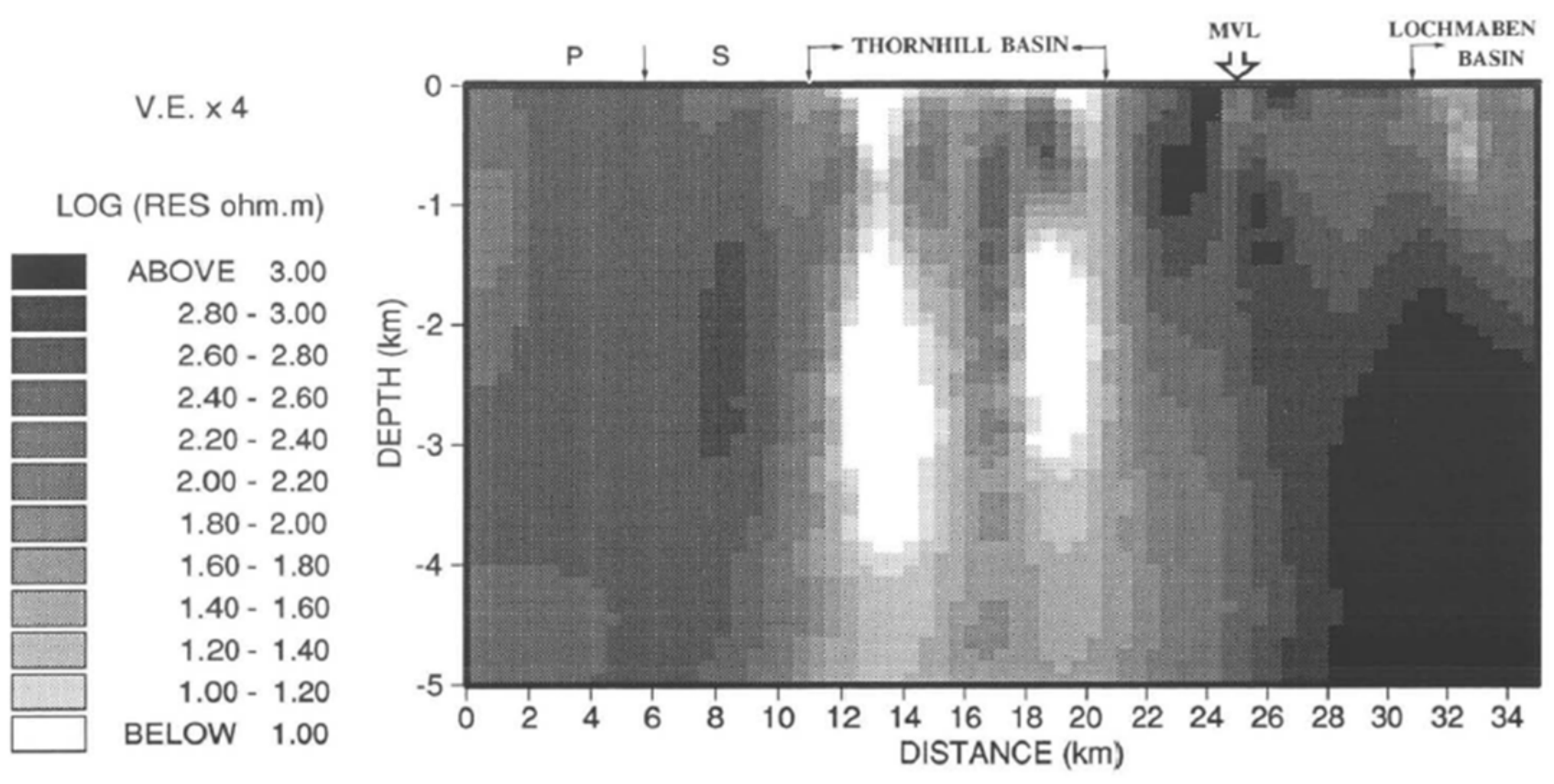

Figure 4. The OCCAM2d smooth, resistivity model obtained at an rms misfit of 2.48. Depth range from 0 to $5 \mathrm{~km}$. Resistivity (ohm $\mathrm{m}$ ) contoured using a logarithmic scale. The values of 3, 2 and 1 represent resistivity values of 1000, 100 and $10 \mathrm{ohm} \mathrm{m}$, respectively. P- Portpatrick Formation ; S Shinnel Formation; MVL- Moffat Valley Lineament. 


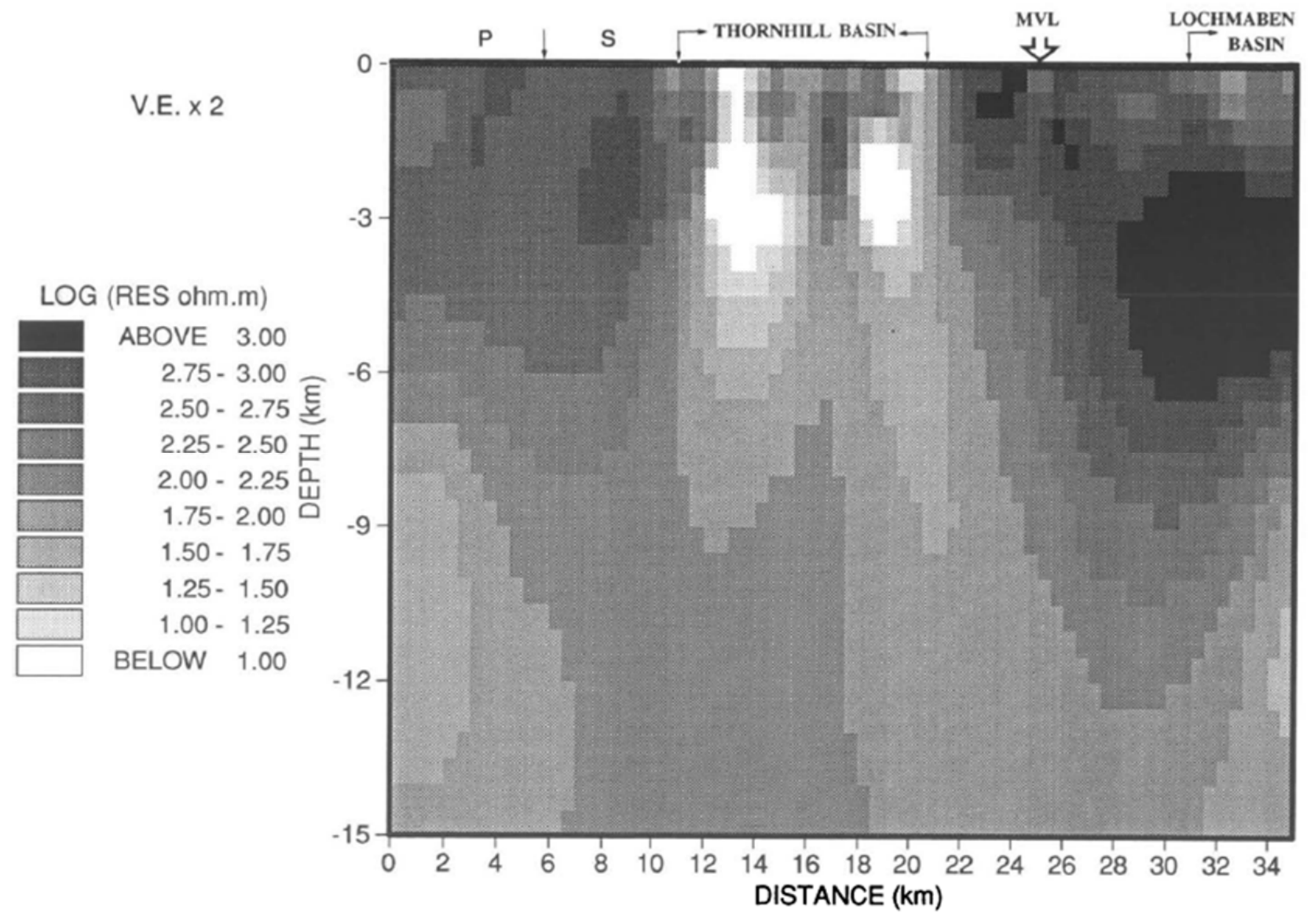

Figure 5. The OCCAM2d smooth, resistivity model obtained at an rms misfit of 2.48. Depth range from 0 to $15 \mathrm{~km}$. Resistivity (ohm.m) contoured using a logarithmic scale. The values of 3, 2 and 1 represent resistivity values of 1000, 100 and $10 \mathrm{ohm} \mathrm{m}$, respectively. P- Portpatrick Formation; S Shinnel Formation; MVL- Moffat Valley Lineament. 